\title{
3-D GCM modelling of thermospheric nitric oxide during the 2003 Halloween storm
}

\author{
A. L. Dobbin, E. M. Griffin, A. D. Aylward, and G. H. Millward \\ Atmospheric Physics Laboratory, Department of Physics and Astronomy, University College London, Gower street, London, \\ WC1E 6BT, UK
}

Received: 4 January 2006 - Revised: 19 June 2006 - Accepted: 4 July 2006 - Published: 20 September 2006

Part of Special Issue "Twelfth EISCAT International Workshop"

\begin{abstract}
Numerical modelling of thermospheric temperature changes associated with periods of high geomagnetic activity are often inaccurate due to unrealistic representation of nitric oxide (NO) densities and associated $5.3-\mu \mathrm{m}$ radiative cooling. In previous modelling studies, simplistic parameterisations of NO density and variability have often been implemented in order to constrain thermospheric temperature predictions and post storm recovery timescales during and following periods of high auroral activity. In this paper we use the University College London (UCL) 3-D Coupled Thermosphere and Middle Atmosphere (CMAT) General Circulation Model to simulate the 11-day period from 23 October to 3 November 2003, during which the Earth experienced some of the largest geomagnetic activity ever recorded; the so called "Halloween storm". This model has recently been updated to include a detailed self consistent calculation of NO production and transport. Temperatures predicted by the model compare well with those observed by the UCL Fabry Perot Interferometer at Kiruna, northern Sweden, when changes in solar and auroral activity are taken into account in the calculation of NO densities. The spatial distribution of predicted temperatures at approximately $250-\mathrm{km}$ altitude is also discussed. Simulated NO densities at approximately $110 \mathrm{~km}$ are presented. Large quantities of NO are found to be present at to the equator, one to two days after the most intense period of geomagnetic activity. This is the first 3-D GCM simulation of NO production and transport over the 2003 Halloween storm period.
\end{abstract}

Keywords. Atmospheric composition and structure (Thermosphere-composition and chemistry; Pressure, density, and temperature; Airglow and aurora)

Correspondence to: A. L. Dobbin

(alison@apl.ucl.ac.uk )

\section{Introduction}

A well established link between auroral energy input and thermospheric nitric oxide (NO) concentration has been demonstrated by numerous observational and modelling studies (e.g. Gerard and Barth, 1977; Barth, 1992; Solomon et al., 1999; Baker et al., 2001; Barth et al., 2003; Dobbin et al., 2006). The abundance of high latitude NO is directly affected by the flux of precipitating electrons which act to ionise and dissociate molecular nitrogen. These processes result in enhanced concentrations of excited state atomic nitrogen, which in turn leads to enhanced levels of NO production in the lower thermosphere. During periods of high geomagnetic activity, Joule heating also contributes to increased NO production via the temperature sensitive reaction between ground state atomic nitrogen and molecular oxygen. Enhancements in temperature and molecular oxygen density lead to excess NO at altitudes above $140 \mathrm{~km}$. Siskind et al. (1989) and Richards (2004), suggested that mid latitude peak NO densities (occurring around $110 \mathrm{~km}$ ) could be enhanced as excess NO created above $140 \mathrm{~km}$ diffuses to lower altitudes. Recent modelling and observational studies suggest that meridional winds act to transport excess NO produced at auroral latitudes to both mid and low latitudes (Barth and Bailey, 2004; Barth et al., 2003; Dobbin et al., 2006). Considering the chemical and radiative properties of $\mathrm{NO}$, the density distribution may give some indication of the temporal and spatial distribution of energy deposition in the thermosphere.

A key property of the thermosphere that is strongly influenced by NO abundance is the thermal response to periods of enhanced geomagnetic activity. 5.3- $\mu \mathrm{m}$ radiative emission by excited NO is an important cooling mechanism in the lower thermosphere (Maeda et al., 1992). Enhanced levels of NO created by high auroral activity will therefore result in an increase in 5.3- $\mu \mathrm{m}$ radiative cooling. As well as increasing NO production, enhanced auroral energy deposition

Published by Copernicus GmbH on behalf of the European Geosciences Union. 
influences the collisional excitation of NO, which occurs primarily via inelastic collisions with atomic oxygen. A change in the abundance of $\mathrm{O}$ is consequently accompanied by a change in the amount of excited NO molecules. Increases in the background temperature associated with Joule heating can act to increase the rate of collisional excitation. Recent observations of infrared radiance by the SABER instrument onboard the Thermosphere-Ionosphere Mesosphere Energetics and Dynamics (TIMED) satellite, show dramatic increases in 5.3- $\mu \mathrm{m}$ emission during periods of enhanced solar and geomagnetic activity (Mlynczak et al., 2003). Increases in 5.3- $\mu \mathrm{m}$ cooling act to damp thermospheric temperature increases arising from increased geomagnetic activity, and reduce timescales of temperature relaxation in the recovery phase of a storm.

From the processes described above, it follows that any attempt to simulate the thermal response of the atmosphere to auroral forcing, must include a reasonable representation of NO chemistry and transport. While numerous modelling studies of the response of the thermosphere and ionosphere to geomagnetic storms have been performed (e.g. Fuller-Rowell et al., 1994; Fuller-Rowell et al., 1996a; Fujiwara et al., 1996; Field et al., 1998; Burns et al., 2004), few have included a comprehensive self consistent calculation of NO production and transport. Maeda et al. (1989) used an empirical formula to derive a geomagnetic activity dependence for NO density in a zonally averaged thermospheric model. The study showed that the activity dependent variability of NO must be taken into account in order to reasonably simulate both the response and recovery of thermospheric temperatures to changing geomagnetic activity. When auroral NO production was not included in their simulations of increased geomagnetic activity, the modelled temperature response was drastically overestimated. The simulated relaxation time following subsidence of activity was also considerably slower than that of observations. Modelling studies of the ionospheric response to geomagnetic forcing also exhibit prolonged recovery times in simulated peak electron densities $(N m \mathrm{~F} 2)$ when odd nitrogen chemistry is not well represented (Fuller-Rowell et al., 2000). Wells et al. (1997) showed that when the effects of NO cooling were included in the CTIP model, via application of an "effective heating efficiency", the representation of quiet time neutral temperatures, composition and maximum plasma frequency ( $f o \mathrm{~F} 2)$ were substantially improved in the summer hemisphere.

The purpose of this paper is to describe the results of a GCM simulation of the 11-day period from 23 October to 3 November 2003 during which the Earth experienced one of the largest geomagnetic storms ever recorded, commonly referred to as the "Halloween storm". The response of the thermosphere to this period of enhanced geomagnetic activity has been simulated using the CMAT model which has recently been updated to include a fully self-consistent calculation of odd nitrogen chemistry and transport (Dobbin et al., 2006; Dobbin, 2005). In order to assess the importance and accuracy of the CMAT modelled NO densities on the thermal response and recovery of the thermosphere, two CMAT simulations have been performed. In the first, NO densities were calculated by the CMAT chemical scheme, taking into account activity dependent changes in solar and auroral NO production. The second simulation used CMAT NO densities calculated on the first day of the simulation when activity levels were low, for the full 11 day period. A brief description of the CMAT GCM is given in the next section, along with descriptions of the simulations performed. Comparison of simulated temperatures at $250-\mathrm{km}$ altitude with those measured by the University College London Fabry Perot Interferometer at Kiruna, northern Sweden $\left(67.8^{\circ} \mathrm{N}, 20.4^{\circ} \mathrm{E}\right.$ in geographic coordinates) are then presented. The horizontal distribution of temperature changes at $250-\mathrm{km}$ altitude arising from the high energy forcing are presented in Sect. 4, followed by the time varying peak NO distribution (at 110-km altitude) calculated by the model. While there has been much speculation on the horizontal distribution of NO following high geomagnetic activity (Barth and Bailey, 2004; Marsh et al., 2004), no 3-D modelling simulations of a major storm event have been performed to date. These results comprise the first predictions of the spatial and temporal distribution of $\mathrm{NO}$ over the "2003 Halloween storm".

\section{The CMAT GCM time-dependent storm simulation}

The coupled middle atmosphere and thermosphere model (CMAT) is an extension of the University College London time dependent 3-D Coupled Thermosphere Ionosphere Plasmasphere (CTIP) model (see Fuller-Rowell et al., 1996b; Millward et al., 1996). The model solves the nonlinear equations of energy, momentum and continuity on a model grid of $2^{\circ}$ latitude, $18^{\circ}$ longitude and a third scale height, from 10 mbar $(\sim 30 \mathrm{~km})$ to $7.6 \mathrm{pbar}(\sim 300-600 \mathrm{~km})$. A comprehensive mesosphere-thermosphere chemical scheme is included. Radiative cooling due to 5- $\mu \mathrm{m}$ emission from excited NO is calculated as described in Kockarts (1980), with a collisional deactivation rate of $2.4 \times 10^{-11} \mathrm{~cm}^{3} \mathrm{~s}^{-1}$ (Dodd et al., 1999). The model has been presented in detail in Harris (2001) and Dobbin (2005). A description of the version used in this study can be found in Dobbin et al. (2006).

The distribution of particle precipitation and energy flux in CMAT are taken from the statistical model of Fuller-Rowell and Evans (1987) and are based on the TIROS/NOAA auroral particle measurements. Cross-polar-cap electric fields are taken from the model of Foster et al. (1986). Both auroral particle precipitation and cross-polar-cap electric fields are related to a power index (PI), as detailed in Evans et al. (1988). Using 3 hourly planetary $K_{p}$ index values (taken from http://www.sec.noaa.gov) for the time period spanning 12:00 UT on 23 October to 12:00 UT on 3 November 2003, a time series of auroral power index (PI) has been derived. During this period, the Earth experienced a prolonged period 


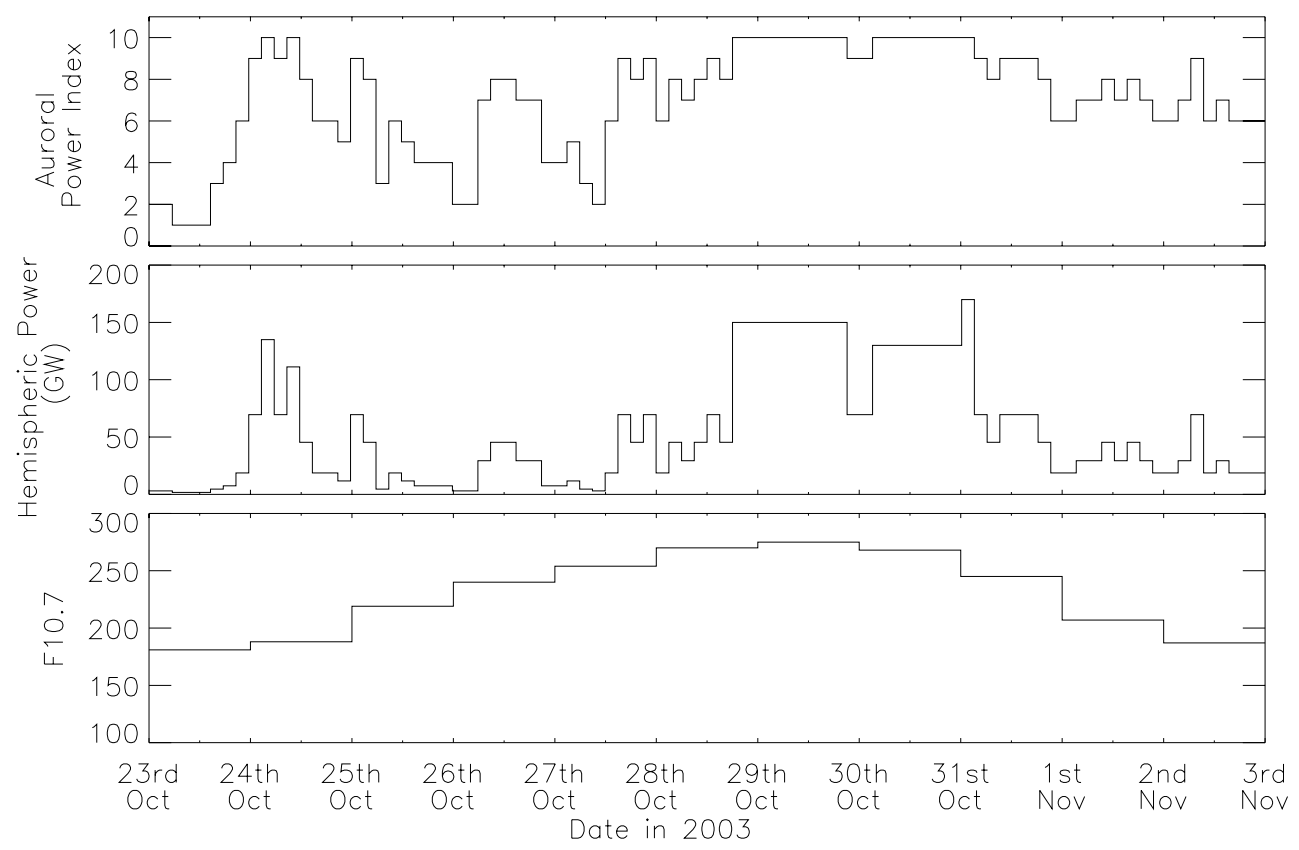

Fig. 1. Auroral power index, hemispheric power and F10.7 inputs used in the CMAT model for simulation of the period from 12:00 UT on 23 October to 12:00 UT on 3 November 2003.

of geomagnetic activity that included one of the largest geomagnetic storms ever recorded. The PI time series was used to determine the flux, energy and distribution of particle precipitation, along with patterns of high latitude convection fields used in the CMAT simulation. The extremely high $K_{p}$ values measured over the 29-31 October exceeded those represented by the statistical patterns used in the model. For these levels of activity, precipitation and electric field patterns of the highest power index (10) were used along with enhanced values of the total hemispheric precipitating power input. The values of hemispheric power used were extrapolated from available data for lower levels of activity, as given by Foster et al. (1986), the total power input to a single hemisphere increasing exponentially with activity. The resulting convection patterns are the same shape to those derived from the highest PI value, but the cross-polar-cap potential and thus energy input is increased. The result is an increase in the magnitude of the electric fields used. The total ionisation rate due to particle precipitation is also increased in proportion to the increase in hemispheric power input. In order to maintain model stability during prolonged periods of very high activity, the hemispheric power input was capped at $150 \mathrm{GW}$ over the 29 and 30 October when the highest levels of activity were measured. The hemispheric power measured by the NOAA POES satellites during this time actually reached a maximum of $554.5 \mathrm{GW}$ in the Northern Hemisphere. The average hemispheric power measured over this time period was $173 \mathrm{GW}$.
The daily solar flux inputs to the CMAT model are derived from the SOLAR2000 empirical model (Tobiska et al., 2000) and are based on the F10.7 proxy for solar activity, also taken from http://www.sec.noaa.gov. The time series of 3 hourly auroral power index and total hemispheric power inputs used in the CMAT simulations are shown in Fig. 1, along with F10.7 values used.

In order to demonstrate the impact of using activity dependent, self-consistently derived NO densities in the calculation of NO radiative cooling rates, a second CMAT run was conducted. In the first simulation, NO cooling was calculated using time-varying self consistently calculated NO densities, taking into account changes in solar and auroral production of NO. In the second however, the NO profile calculated for day 1 of the simulation period (23 October 2003) was used on all subsequent model days. Thus the abundance of NO was unchanged from day to day and unaffected by the changes in solar and auroral energy inputs. In the sections that follow, the first and second CMAT simulations will be referred to as having "variable" and "stable" NO densities respectively.

\section{Neutral temperature over Kiruna}

The Fabry-Perot Interferometer at the Kiruna Esrange Optical Platform System (KEOPS) in Sweden $\left(67.8^{\circ} \mathrm{N}, 20.4^{\circ} \mathrm{E}\right)$ was used to measure the temperature of the neutral atmosphere throughout October and November 2003, when the Earth was subject to dramatic geomagnetic storms. By observing the red line aurora and airglow emission at 630-nm 


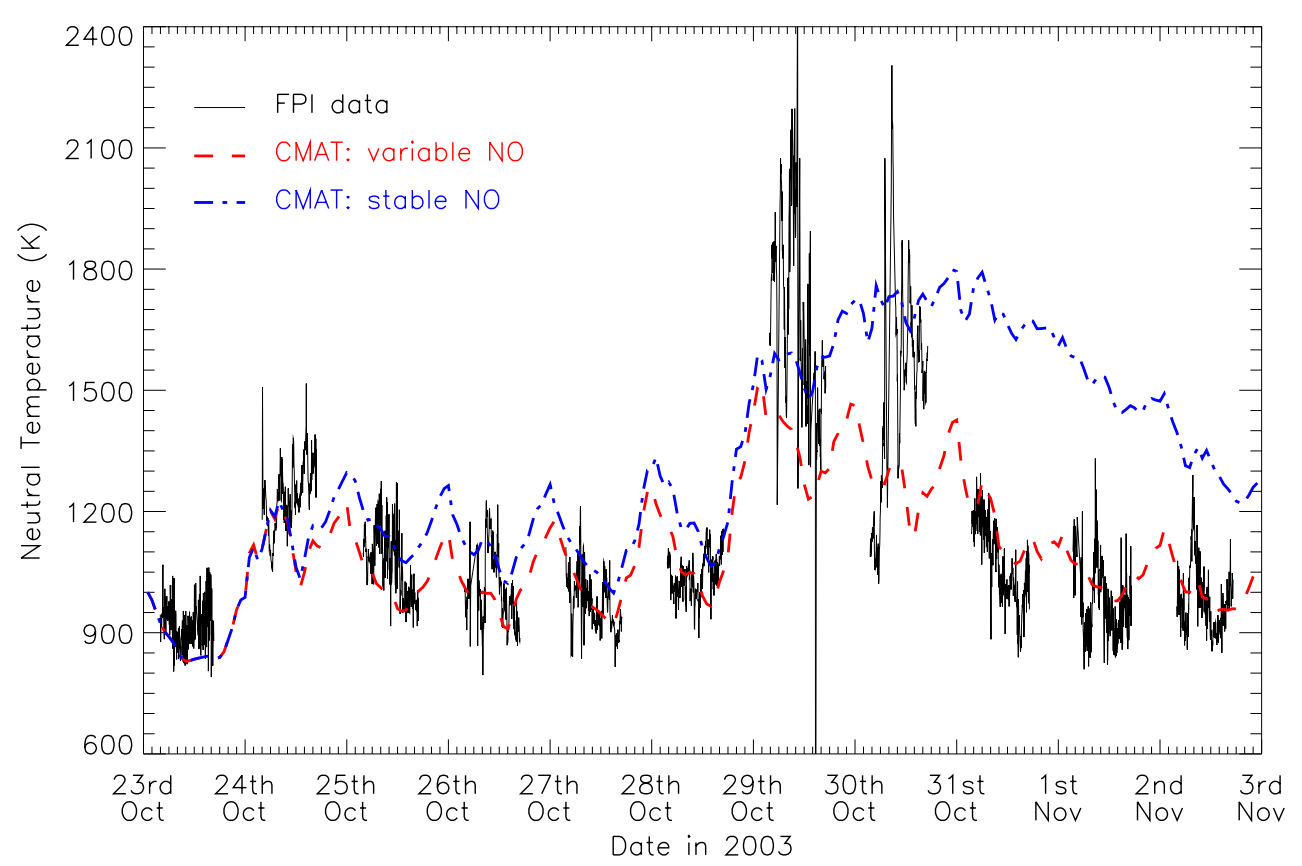

Fig. 2. Neutral temperature at 250-km altitude over Kiruna, northen Sweden, from 12:00 UT on 23 October to 12:00 UT on 3 November 2003, as measured by the UCL FPI and as calculated by the CMAT GCM with daily varying (red line) and constant (blue line) NO densities.

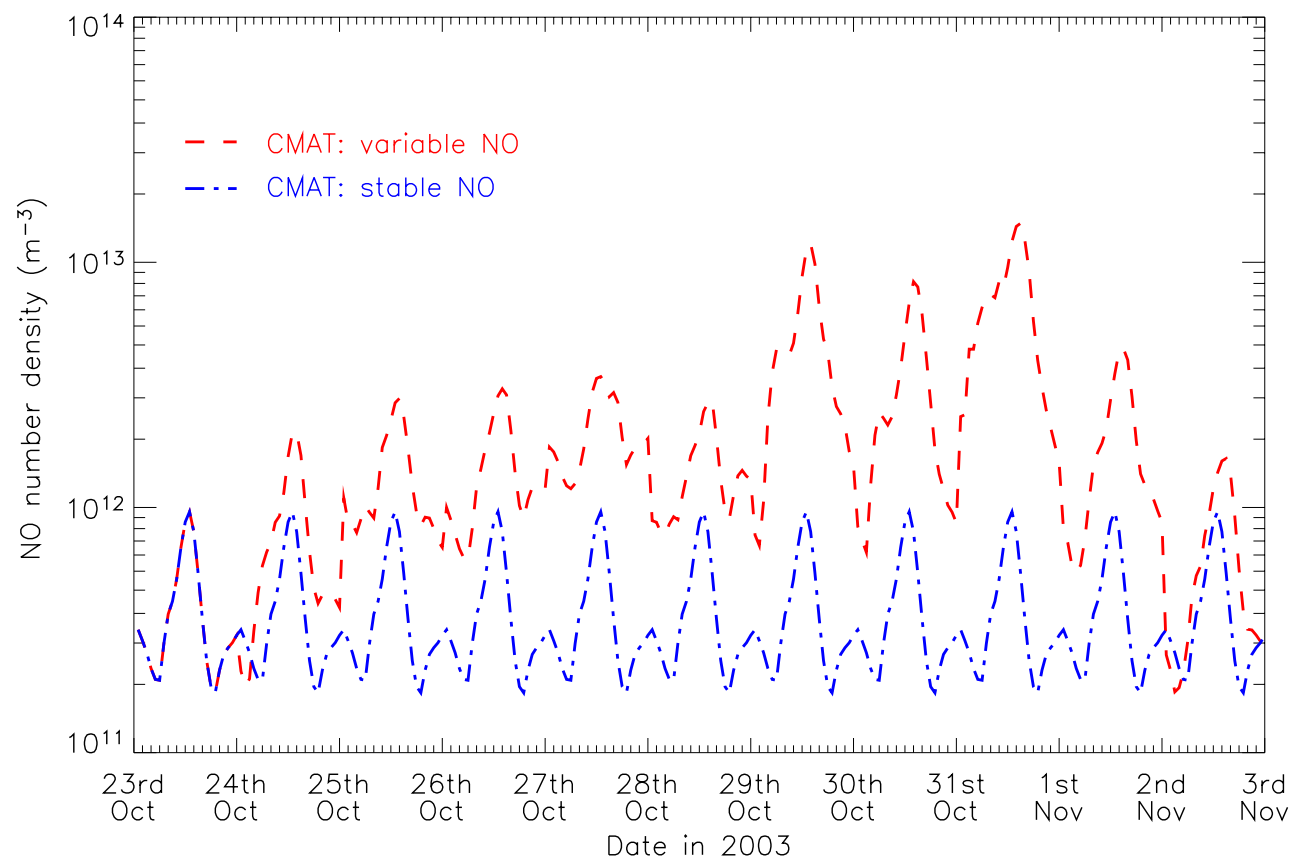

Fig. 3. Nitric oxide number density $\left(\mathrm{m}^{-3}\right)$ at 250-km altitude over Kiruna, northern Sweden, from 12:00 UT on 23 October to 12:00 UT on 3 November 2003, as calculated by the CMAT GCM for the variable NO (red line) and stable NO (blue line) simulations.

wavelength, temperatures and winds at an altitude of around $250 \mathrm{~km}$ can be derived (Aruliah et al., 2005). Neutral temperature measurements taken by the FPI at Kiruna between 12:00 UT 23 October 2003 and 12:00 UT 3 November 2003 are shown in Fig. 2. Also shown are temperatures at
250 -km altitude, $68^{\circ}$ latitude, $20^{\circ}$ longitude, as calculated by the CMAT model in the "variable NO" and "stable NO" simulations described above. Trends in measured temperatures clearly follow the changes in geomagnetic and solar activity, shown in Fig. 1. As might be expected at this latitude, 
rapid temperature changes occur in response to increases or decreases in geomagnetic activity.

For the first six days of the simulated period, the match between variability in measured and calculated temperatures is good for both CMAT model simulations. As expected, the temperatures predicted by both simulations are identical for the first $24 \mathrm{~h}$ of the simulation period, during which the NO concentrations are the same. This trend continues for a further $14 \mathrm{~h}$, after which the temperature predicted by the "stable NO" run starts to increase over that predicted by the "variable NO" run. From this time onwards, temperatures predicted by the CMAT run with "stable" NO densities are higher than those predicted when "variable" NO densities are used. Figure 3 shows the NO number density at approximately $250-\mathrm{km}$ altitude above Kiruna, as calculated by the CMAT model in each model simulation. For the "variable NO" simulation, increases in auroral energy input result in an increase in the abundance of high latitude NO. This in turn leads to an increase in the level of cooling due to $5.3 \mu \mathrm{m}$ radiative emission from collisionally excited NO. The difference in temperatures predicted by the two CMAT simulations can therefore be attributed to the difference in NO cooling, arising from the enhanced concentrations of $\mathrm{NO}$ in the "variable NO" model run.

On 29 October, the 3-hourly $K_{p}$ index changed from $4^{\circ}$, for 03:00 UT to 06:00 UT, to $9^{\circ}$, for 06:00 UT to 09:00 UT. Geomagnetic activity remained at extremely high levels until 15:00 UT on 31 October, after which a reasonably steady decrease to moderate activity occurred. Temperatures measured by the FPI increased dramatically from around $1100 \mathrm{~K}$ at 04:00 UT to over $2000 \mathrm{~K}$ at 20:00 UT on 29 October. At 16:00 UT on 31 October, the observed temperature had relaxed to around $1200 \mathrm{~K}$. As activity levels continued to decrease, so too did the observed temperature, which reached around $950 \mathrm{~K}$ at 00:00 UT on 3 November. For this period, temperatures predicted by the two CMAT simulations are dramatically different. The "variable NO" model run continues to show a diurnal cycle and although the very high temperatures measured on 29 and 30 October are not reached, the temperatures predicted by the model between 31 October and 3 November agree well with the FPI observations. In contrast, the "stable NO" CMAT run predicts an overall increase in temperature between 12:00 UT on 29 and 12:00 UT on 31 October, reaching a maximum of $1800 \mathrm{~K}$, approximately $600 \mathrm{~K}$ greater than that measured by the FPI. The slow rate of thermal recovery that follows the very high activity of 29 to 31 October is a result of insufficient NO cooling associated with the fixed low NO concentration. The realistic post storm thermal recovery predicted by the "variable NO" CMAT model run is thought to be a direct result of accurate calculation of NO concentrations and associated cooling.

As mentioned above, the very high temperatures measured by the FPI between 16:00 UT on 29 and 04:00 UT on 31 October are not reproduced by the "variable NO" CMAT simu- lation, which reaches a maximum of $1500 \mathrm{~K}$ on 29 October. This is the result of limitations in the statistical auroral energy inputs to the model which do not account for the very high levels of geomagnetic activity encountered on those dates. Over periods of moderate to high geomagnetic activity, such as occurred between 18:00 UT on 25 and 06:00 UT on 29 October, the magnitude and variability of the CMAT predicted temperatures are in good agreement with the FPI data.

\section{Meridional variation in thermal response}

The neutral temperature at approximately $250 \mathrm{~km}$ calculated by the "variable NO" CMAT model simulation is shown as a function of geographic latitude and time in Fig. 4, for the period 12:00 UT on 23 October to 12:00 UT on 3 November 2003. As described above, this simulation uses nitric oxide densities that have been calculated self consistently and updated every model time step, taking changes in geomagnetic and solar activity into account. Plots are shown for $0^{\circ}$ and $180^{\circ}$ longitude. The distribution of energy deposition will be different in each longitude sector, depending on the convection and particle precipitation patterns used. A detailed comparison of temperatures in the two plots would therefore be misleading. A qualitative view of the meridional extent of temperature enhancements in the two sectors can however be gained from each plot.

As might be expected, temperatures are generally greater in the Southern Hemisphere which is exposed to greater levels of solar radiation than the Northern Hemisphere at this time of year. Joule heating leads to high latitude temperature enhancements in both hemispheres. The level of Joule heating is directly affected by changes in geomagnetic activity and so therefore, is the temperature of the high latitude thermosphere. Increases of up to $450 \mathrm{~K}$ and $500 \mathrm{~K}$ occur in the high latitude Northern and Southern Hemispheres respectively in response to the dramatic changes in geomagnetic activity on 24 October. In the Northern Hemisphere, the aurorally induced temperature changes are fairly localised and do not extend equatorward of about $60^{\circ}$ latitude. In the Southern Hemisphere, the offset between the geographic and geomagnetic poles is greater, meaning aurorally induced temperature enhancements extend further towards the equator, to around $-40^{\circ}$ latitude. Where increased Joule heating occurs in the day-lit sector of the Southern Hemisphere, temperature enhancements are seen to extend all the way from the pole to the equator. Low and mid latitude locations undergo large increases in heating though the absorption of solar radiation. As expected, a correlation exists between thermospheric temperature and solar activity, via the F10.7 values used in the model.

From 29 to 31 October geomagnetic activity reached extremely high levels. CMAT predicted temperatures at 250-km altitude in the Southern Hemisphere high latitude 

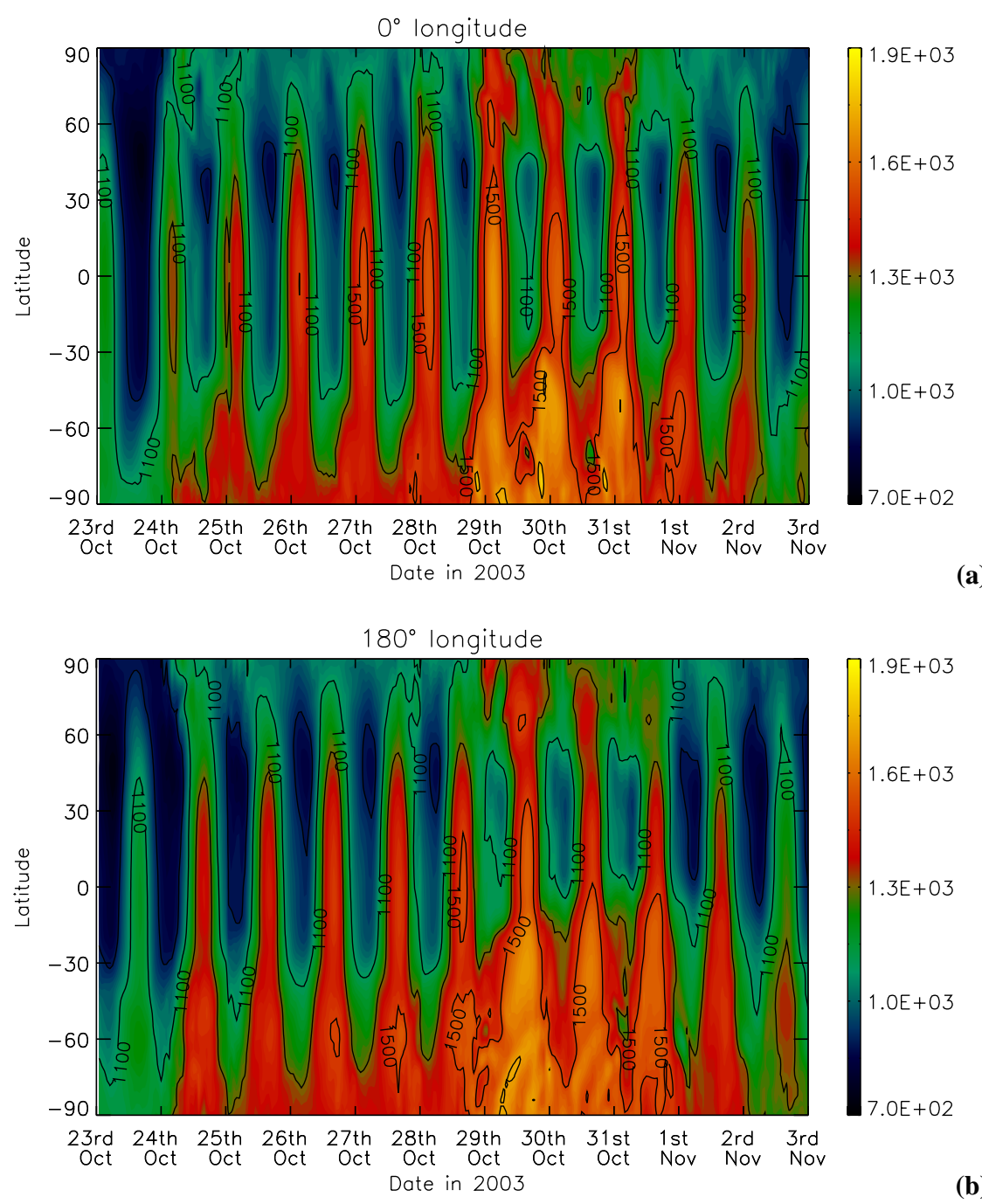

(b)

Fig. 4. CMAT calculated neutral temperature at $250-\mathrm{km}$ altitude as a function of latitude and time at $0^{\circ}$ (a) and $180^{\circ}$ (b) longitude. The time axis covers the period from 12:00 UT 23 October to 12:00UT 3 November 2003. Contour intervals are every 200K.

region reach up to $1750 \mathrm{~K}$. In the Northern Hemisphere, temperatures of just under $1600 \mathrm{~K}$ are predicted. Very high levels of solar heating result from the large F10.7 values used to determine solar flux inputs to the model. As a result, equatorial temperatures reach over $1600 \mathrm{~K}$. At $180^{\circ}$ longitude in the Southern Hemisphere, aurorally induced temperature enhancements reach within $10^{\circ}$ latitude of the equator in the early hours of 1 November. While expansion of the auroral oval will contribute to the equatorward spread of Joule heating, the large temperatures predicted at these low latitudes are almost certainly the result of transport. Strong meridional winds are induced by pressure gradients that result from Joule heating. These winds act to transport energy and chemical constituents to lower latitudes (e.g. Fuller-Rowell et al., 1994).

\section{Evolution of nitric oxide distribution}

Figure 5 shows the nitric oxide number densities calculated by the "variable NO" CMAT simulation at approximately $110-\mathrm{km}$ altitude as a function of geographic latitude and time. Plots are shown for $0^{\circ}$ and $180^{\circ}$ longitude. The time series covers the period from 12:00 UT on 23 October to 12:00 UT on 3 November 2003. Different scales have been used for the $0^{\circ}$ and $180^{\circ}$ longitude plots so as to ensure features in NO distributions are clearly visible. The overall increase in NO number density is in line with observations from the HALOE instrument onboard the UARS satellite which shows a significant increase in $\mathrm{NO}_{\mathrm{x}}$ density over the active period. Jackman et al. (2005) reported an increase in observed $\mathrm{NO}_{\mathrm{x}}\left(\mathrm{NO}+\mathrm{NO}_{2}\right)$ of over 20 ppbv throughout the period from 30 October through 7 November in the Southern 

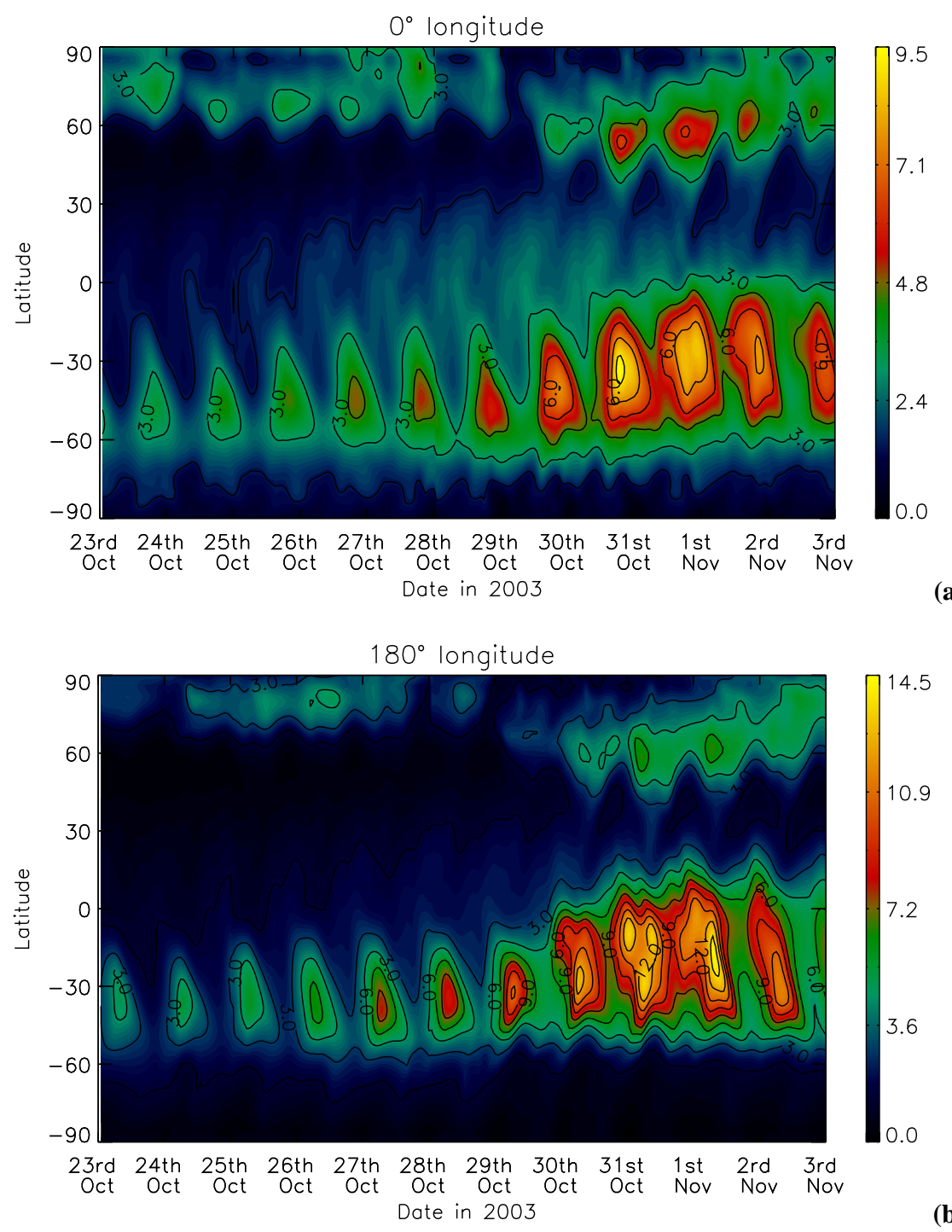

(a)

Fig. 5. CMAT calculated nitric oxide number density $\left(\times 10^{14} \mathrm{~m}^{-3}\right)$ at approximately $110 \mathrm{~km}$ altitude as a function of latitude and time at $0^{\circ}$ (a) and $180^{\circ}$ (b) longitude. The time axis covers the period from 12:00 UT 23 October to 12:00 UT 3 November 2003. Contour intervals are every $1.5 \times 10^{14} \mathrm{~m}^{-3}$.

Hemisphere polar lower mesosphere. In the middle to upper mesosphere, maximum enhancements were observed between 30 and 31 October.

The concentrations of NO at high latitudes are greater than those at low latitudes due to enhanced production of NO associated with particle precipitation. Peak densities in the Northern Hemisphere occur closer to the pole than those in the south. This is a result of the increased offset between geographic and geomagnetic poles in the Southern Hemisphere. The NO abundance clearly responds to changes in geomagnetic activity. At $0^{\circ}$ longitude, maximum concentrations of just under $9.0 \times 10^{14} \mathrm{~m}^{-3}$ occur in the Southern Hemisphere between $-30^{\circ}$ and $-40^{\circ}$ geographic latitude, around midday on the 31 October and 1 November. On the same dates, maxima of nearly $14 \times 10^{14} \mathrm{~m}^{-3}$ are predicted to exist in the Southern Hemisphere at $180^{\circ}$ longitude, between $-10^{\circ}$ and $-30^{\circ}$ latitude. The maxima occur between 12:00 UT and 22:00 UT. While the greatest increases in temperature occurred very rapidly after changes in geomagnetic activity, the maximum NO concentrations occur one to two days after the onset of a period of high activity.

Previous studies of NO transport have often used longitudinally averaged satellite data (e.g. Barth and Bailey, 2004). The results presented here show that there is a significant difference between NO production and transport in different longitude sectors. The amount of NO produced at any point on the globe is dependent on geographic location in relation to the regions of solar and auroral energy input. It follows 


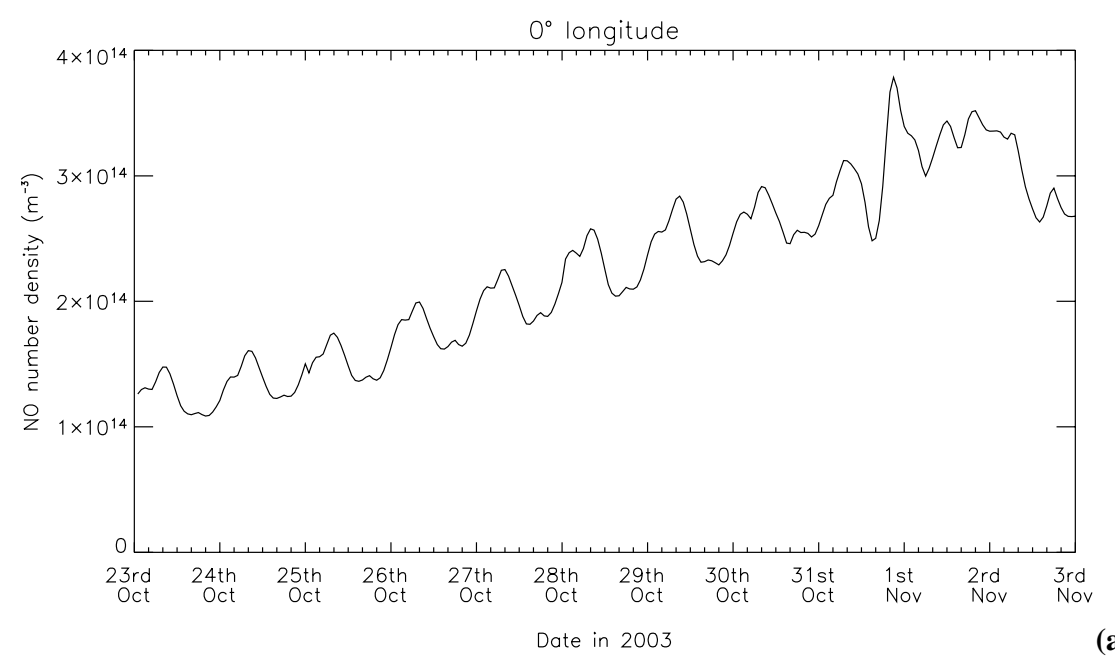

(a)

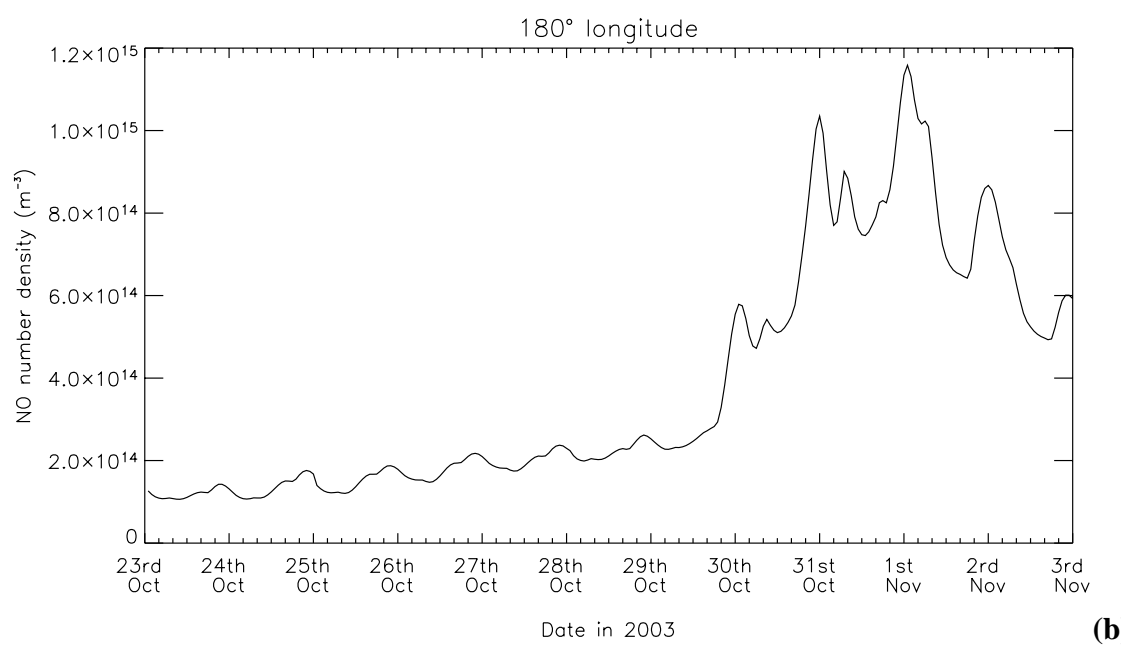

Fig. 6. Equatorial nitric oxide number density $\left(\mathrm{m}^{-3}\right)$ at approximately $110-\mathrm{km}$ altitude, for $0^{\circ}$ (a) and $180^{\circ}$ (b), as calculated by the CMAT model for the period 12:00 UT 23 October to 12:00 UT 3 November 2003.

that longitudinal differences in the spatial distribution and strength of these energy inputs will result in different NO concentrations. Photodissociation by solar UV is a primary NO destruction mechanism. The amount of time for which NO is exposed to day light has an important effect on its lifetime and availability for transport. As discussed in Dobbin et al. (2006), the time lag in the maximum response of NO density to high energy auroral forcing is dependent on geographic location in relation to the region of energy input, and possibly the local time at which auroral forcing occurs.

For the time period modelled here, the high latitude regions of the Northern Hemisphere are less affected by solar radiation than equivalent latitudes in the Southern Hemisphere. This means the effects of aurorally produced NO can be more easily recognized than in the Southern Hemisphere where the sources of NO production are indistinguishable. The geographic latitudes at which NO maxima occur in the
Northern Hemisphere range between $80^{\circ}$ on the 28 October, and $50^{\circ}$ on the 31 October. The peak clearly moves towards the equator as geomagnetic activity is increased. Expansion of the auroral oval will contribute to this equatorward progression, as will transport of NO by strong meridional winds and diffusion of NO from above.

At mid and low latitudes, the calculated concentrations of NO increase dramatically over the simulation period. Figure 6 shows the equatorial NO number density at approximately $110-\mathrm{km}$ altitude for $0^{\circ}$ and $180^{\circ}$ longitude. The diurnal variation in NO density results from the change in solar zenith angle over the day. At $0^{\circ}$ longitude this variation is clearly seen from 12:00 UT on 23 October to the early hours of 1 November, after which a contribution from aurorally produced NO acts to alter the diurnal structure. The gradual increase in daily NO concentrations seen between the 23 and 30 October results from increases in the soft X-ray solar flux 
input to the model, as determined by the F10.7. At around 22:00 UT on 23 and 29 October, peaks in the NO density of 1.5 and $2.9 \times 10^{14} \mathrm{~m}^{-3}$ are predicted. The F10.7 values used on these dates are 181 and 275, respectively (see Fig. 1). On 1 November, a peak NO number density of just under $3.3 \times 10^{14} \mathrm{~m}^{-3}$ is predicted to occur at around 08:00 UT. The F10.7 used for this day was 245 . The fact that this large NO peak is created at 08:00 UT on a day when the trend in F10.7 is downward indicates that there is a significant contribution from aurorally produced NO.

At $180^{\circ}$ longitude, the equatorial $\mathrm{NO}$ density also displays a strong diurnal variability from 23 to 29 October, with peak NO densities of 1.5 and $2.6 \times 10^{14} \mathrm{~m}^{-3}$ occurring close to 10:00 UT on the 24 and 29 October respectively. In the early hours of 30 October, a large increase in NO density is predicted, approximately $20 \mathrm{~h}$ after the start of the very intense storm period. By 12:00 UT on 1 November, the NO density has reached a peak of $11.6 \times 10^{14} \mathrm{~m}^{-3}$. This very high number density is attributed to aurorally produced NO that has been transported from high to low latitudes, and to the downward diffusion of NO produced above $140 \mathrm{~km}$. While the equatorial NO density does start to drop after this peak, large concentrations are still present at the end of the simulation period.

\section{Conclusions}

The UCL CMAT GCM has been used to simulate the period from 12:00 UT on 23 October to 12:00 UT on 3 November 2003, during which the Earth experienced extremely high levels of geomagnetic activity. Neutral temperatures calculated by the CMAT model in two simulations were compared with FPI measurements made in Kiruna in northern Sweden. The first simulation used time varying, activity dependent NO densities, as calculated by the CMAT chemical scheme. The second used quiet time, diurnally repeatable NO densities. The magnitude and variability of the CMAT predicted temperatures matched the FPI data well when activity dependent NO densities were used, although the very high temperatures recorded at the peak of the largest storm were underestimated by the model. When the NO concentration was maintained at a quiet time daily profile, temperatures predicted were higher than those observed and the timescales of post-storm recovery were overestimated. The improved temperature variability modelled by CMAT with variable NO is attributed to the inclusion of realistic self-consistent calculation of NO concentration and associated radiative cooling.

The meridional distribution of temperature enhancements resulting from the geomagnetic storm at approximately $250-\mathrm{km}$ altitude has been assessed. For the dates in question, high latitudes in the Northern Hemisphere are less influenced by solar radiation than the equivalent latitudes in the south. Temperatures are therefore generally greater in the south than in the north. High latitude temperatures re- spond to changes in geomagnetic activity as the associated level of Joule heating changes. In the Northern Hemisphere, temperature changes associated with the rapid increase in geomagnetic activity on 24 October are restricted to latitudes poleward of about $60^{\circ}$ geographic latitude. In the Southern Hemisphere, aurorally induced temperature enhancements remain at latitudes poleward of about $-40^{\circ}$ latitude. During the period of maximum activity from 29 to 31 October, CMAT predicted temperatures reached up to $1750 \mathrm{~K}$ and $1600 \mathrm{~K}$ in the Southern and Northern Hemispheres, respectively. Aurorally induced temperature enhancements reached $10^{\circ}$ south of the equator in the early hours of 1 November. This is the result of strong meridional winds associated with high levels of Joule heating. Increases in the F10.7 solar activity proxy throughout the first 7 days of the simulation lead to enhanced equatorial temperatures of up to $1600 \mathrm{~K}$.

Nitric oxide number densities at the peak altitude of $110 \mathrm{~km}$ respond to changes in the solar and geomagnetic energy inputs. The magnitude and location of NO density peaks are highly variable, depending on location with respect to the auroral oval, transport of NO by meridional winds, diffusion of NO from altitudes above $140 \mathrm{~km}$ and changes in solar flux and particle precipitation inputs. The latitude at which maxima occur moves towards the equator as geomagnetic activity increases and the auroral oval expands. Maximum concentrations modelled by the CMAT model reach just less than $14 \times 10^{14} \mathrm{~m}^{-3}$ and occur between $-10^{\circ}$ and $-30^{\circ}$ geographic latitude, $180^{\circ}$ longitude in the Southern Hemisphere. The peaks in NO concentration occur one to two days after the onset of a period of high activity.

Prior to the large increases in geomagnetic activity seen on the 29 October, equatorial NO densities are largely controlled by diurnal variations in the solar energy input. A steady increase in low latitude NO abundance occurs over the simulation period as a result of increases in solar activity, described by the F10.7 proxy. Enhancements in the equatorial NO budget start to occur 1 day after the onset of the strongest storm forcing, depending on location. These enhancements arise as NO produced at high latitudes is transported equatorward by strong meridional winds. A contribution from downward diffusion of $\mathrm{NO}$ is also possible. Maximum equatorial NO densities of 3.3 and $11.6 \times 10^{14} \mathrm{~m}^{-3}$ are predicted to occur at 08:00 UT and 12:00 UT on 1 November, at longitudes of $0^{\circ}$ and $180^{\circ}$, respectively.

Acknowledgements. The research was supported by grants from the U.K. Particle Physics and Astronomy Research Council (PPARC). The CMAT simulations were carried out on the Enigma supercomputer at the UCL HiPerSPACE computing centre, which is funded by PPARC. SOLAR2000 Research Grade V2.27 historical irradiances are provided courtesy of W. K. Tobiska and SpaceWx. These historical irradiances have been developed with funding from the NASA UARS, TIMED, SOHO, and SDO missions as well as the JSDAP and LWS programs.

Topical Editor M. Pinnock thanks M. V. Codrescu and another referee for their help in evaluating this paper. 


\section{References}

Aruliah, A. L., Griffin, E. M., Aylward, A. D., Ford, E. A. K., Kosch, M. J., Davis, C. J., Howells, V. S. C., Pryse, S. E. , Middleton, H. R., and Jussila, J.: First direct evidence of meso-scale variability on ion-neutral dynamics using co-located tristatic FPIs and EISCAT radar in Northern Scandinavia, Ann. Geophys., 23, 147-162, 2005, http://www.ann-geophys.net/23/147/2005/.

Baker, D. N., Barth, C. A., Mankoff, K. E., Kanekal, S. G., Bailey, S. M., Mason, G. M., and Mazur, J. E.: Relationship between precipitating auroral zone electrons and lower thermopsheric nitric oxide densities: 1998-2000, J. Geophys. Res., 106 (A11) 24 465-24 480, 2001.

Barth, C. A.: Nitric Oxide in the Lower Thermosphere, Planet. Space. Sci., 40, No 2/3, 315-336, 1992.

Barth, C. A. and Bailey, S. M.: Comparison of a thermospheric photochemical model with Student Nitric Oxide Explorer (SNOE) observations of nitric oxide, J. Geophys. Res., 109, A03304, doi:10.1029/2003JA010227, 2004.

Barth, C. A., Mankoff, K. D., Bailey, S. M., and Solomon, S. C.: Global Observations of Nitric Oxide in the Thermosphere, J. Geophys. Res., 108 (A1), 1027, doi:10.1029/2002JA009458, 2003.

Burns, A. G., Killeen, T. L., Wang, W., and Roble, R. G.: The solarcycle-dependent response of the thermosphere to geomagnetic storms, J. Atmos. Sol. Terr. Phys., 66, 1-14, 2004.

Dobbin, A. L.: Modelling studies of possible coupling mechanisms between the upper and middle atmosphere, Ph.D. Thesis, University of London, London, UK, 2005.

Dobbin, A. L., Aylward, A. D., and Harris, M. J.: 3D GCM Modeling of nitric oxide in the lower thermosphere, J. Geophys. Res., 111, A07314, doi:10.1029/2005JA011543, 2006.

Dodd, J. A., Lockwood, R. B., Hwang, E. S., Miller, S. M., and Lipson, S. J.: Vibrational relaxation of $\mathrm{NO}(v=1)$ by oxygen atoms, J. Chem. Phys. 111, 3498-3507, 1999.

Evans, D. S., Fuller-Rowell, T. J., Maeda, S., and Foster, J. C.: Specification of the heat input to the thermosphere from magnetic proceses using TIROS/NOAA auroral particle observations, Advances in Astronautical Science, 65, 1649-1667, 1988.

Field, P. R., Rishbeth, H., Moffett, R. J., Idenden, D. W., FullerRowell, T. J., Millward, G. H., and Aylward, A. D.: Modelling composition changes in F-layer storms, J. Atmos. Sol. Terr. Phys., 60, 5, 523-543, 1998.

Foster, J. C., Holt, J. M., Musgrove, R. G., and Evans, D. S.: Ionospheric convection associated with discrete levels of particle precipitation, Geophys. Res. Lett., 13, 656-659, 1986.

Fuller-Rowell, T. J. and Evans, D. S.: Height-integrated Pedersen and Hall conductivity patterns inferred from the TIROS-NOAA satellite data, J. Geophys. Res., 92, 7606, 1987.

Fuller-Rowell, T. J., Codrescu, M. V., Moffett, R. J., and Quegan, S.: Response of the thermosphere and ionosphere to geomagnetic storms. J. Geophys. Res., 99 (A3), 3893-3914, 1994.

Fuller-Rowell, T. J., Codrescu, M. V., Risbeth, H., Moffett, R. J., and Quegan, S.: On the seasonal response of the thermosphere and ionosphere to geomagnetic storms, J. Geophys. Res., 101 (A2), 2343-2353, 1996a.

Fuller-Rowell, T. J., Rees, D., Quegan, S., Moffett, R. J., Codrescu, M. V., and Millward, G. H.: A coupled thermosphere ionosphere model (CTIM), Solar terrestrial energy program (STEP), Handbook of ionospheric models, edited by: Schunk, R. W., 1996 b.
Fuller Rowell, T. J., Codrescu, M. V., and Wilkinson, P.: Quantitative modeling of the ionospheric response to geomagnetic activity, Ann. Geophys., 18, 766-781, 2000, http://www.ann-geophys.net/18/766/2000/.

Fujiwara, H., Maeda, S., Fukunishi, H., Fuller-Rowell, T. J., and Evans, D. S.:Global variations of thermospheric winds and temperatures caused by substorm energy injection, J. Geophys. Res., 101(A1), 225-240, 1996.

Gerard, J. C. and Barth, C. A.: High-latitude nitric oxide in the lower thermosphere, J. Geophys. Res., 82, 674-680, 1977.

Harris, M. J.: A new coupled middle atmosphere and thermosphere circulation model: Studies of dynamic, energetic and photochemical coupling in the middle and upper atmosphere, $\mathrm{PhD}$. Thesis, University of London, 2001.

Jackman, C. H., DeLand, M. T., Labow, G. J., Fleming, E. L., Weisenstein, D. K., Ko, M. K. W., Sinnhuber, M., and Russell, J. M.: Neutral atmospheric influences of the solar proton events in October-November 2003, J. Geophys. Res., 110, A09S27, doi:10.1029/2004JA010888, 2005.

Kockarts, G.: Nitric Oxide Cooling in the terrestrial Thermosphere, Geophys. Res. Lett., 7, No. 2, 137-140, 1980.

Maeda, S., Fuller-Rowell, T. J., and Evans, D. S.: Zonally averaged dynamical and compositional response of the thermosphere to auroral activity during September 18-24, 1984, J. Geophys. Res., 94, 16869-16883, 1989.

Maeda, S., Fuller-Rowell, T. J., and Evans, D. S.: Heat budget of the thermosphere and temperature variations during the recovery phase of a geomagnetic storm, J. Geophys. Res., 97 (A10), 14,947-14,957, 1992.

Marsh, D. R., Solomon, S. C., and Reynolds, A. E.: Empirical model of nitric oxide in the lower thermosphere, J. Geophys. Res., 109, A07301, doi:10.1029/2003JA010199, 2004.

Millward, G., Moffett, R. J., Quegan, S., and Fuller-Rowell, T. J.: A Coupled Thermosphere-Ionosphere-Plasmasphere Model (CTIP), Solar Terrestrial Energy Program (STEP) Handbook, edited by: Schunk, R. W., 1996.

Mlynczak, M., Martin-Torres, F. J., Russell, J., et al.: The natural thermostat of nitric oxide emission at $5.3 \mu \mathrm{m}$ in the thermosphere observed during the solar storms of April 2002, Geophys. Res. Lett., 30(21), 2100, doi:10.1029/2003GL017693, 2003.

Richards, P. G.: On the increase in nitric oxide density at midlatitudes during ionospheric storms, J. Geophys. Res., 109, doi:10.1029/2003JA010110, 2004.

Siskind, D. E., Barth, C. A., and Roble, R. G.: The response of thermospheric nitric oxide to an auroral storm: 1 . Low and middle latitudes, J. Geophys. Res., 94(A12), 16885-16 898, 1989.

Solomon, S. C., Barth, C. A., and Bailey, S. M.: Auroral production of nitric oxide measured by the SNOE satellite, Geophys. Res. Lett., 26, 1259-1262, 1999.

Tobiska, K. W., Woods, T., Eparvier, F., Viereck, R., Floyd, L., Bouwer, D., Rottoman, G., and White, O. R.: The SOLAR2000 empirical solar irradiance model and forecast tool, J. Atmos. Sol. Terr. Phys., 62, 1233-1250, 2000.

Wells, G. D., Rodger, A. S., Moffett, R. J., Bailey, G. J., and Fuller-Rowell, T. J.: The effects of nitric oxide cooling and the photodissociation of molecular oxygen on the thermosphere/ionosphere system over the Argentine Islands, Ann. Geophys., 15, 355-365, 1997, http://www.ann-geophys.net/15/355/1997/. 